Pediat. Res. 6: 705-712 (1972)

Erythrocytes glucose-6-phosphate dehydrogenase isoenzymes neonate

nicotinamide-adenine

dinucleotide phosphate

\title{
Change in Electrophoretic Mobility of Glucose- 6-Phosphate Dehydrogenase with Aging of Erythrocytes
}

\author{
Bohdan Bakay ${ }^{[23]}$, William L. Nyhan, and Ellen St. J. Monkus \\ Departments of Pediatrics, University of California, San Diego, La Jolla, California and University of Miami, Miami, Florida, USA
}

\section{Extract}

Electrophoretic properties of glucose-6-phosphate dehydrogenase (G6PD) were studied in mother-infant pairs and in young and old erythrocytes of adults. G6PD isoenzymes of erythrocytes of newborn infants migrated at rates $3-4 \%$ faster than the corresponding isoenzymes of maternal exythrocytes. Analysis of hemolysates of young and old erythrocytes of adults revealed that G6PD of young cells also moved about $3 \%$ faster than that of old cells. In contrast, active enzyme sedimentation analysis revealed that the G6PD enzyme proteins of old and young erythrocytes of adults, of newborns, and of their mothers sedimented with essentially identical rates $\left(S_{20, w}=6.8\right)$. Migration in gels of different acrylamide concentrations and velocity sedimentation analysis indicated that the G6PD of old and of young erythrocytes was in the same state of aggregation. Extensive equilibration of the hemolysates with nicotinamide-adenine dinucleotide phosphate (NADP) by filtration through Sephadex G-25 induced a clear increase in the migration rate of the G6PD of old cells of adults and of mothers at term to the rate characteristic of the enzyme of neonates and of young cells of adults. Experiments in which NADP was labeled with ${ }^{14} \mathrm{C}$ indicated that, in the process of gel filtration, the NADP content of the aged G6PD was restored. Thus the rate of migration of G6PD in acrylamide gel seems to be a function of the amount of NADP bound.

\section{Speculation}

Rates of electrophoretic migration of G6PD of the erythrocytes of infants and of young cells of adults were faster than the rates observed in adult cells; this, at first, was thought to be genetically determined, as with fetal hemoglobin. However, thorough testing proved that the difference was one of charge mediated by NADP, the concentration of which is a function of the age of the erythrocytes. There are numerous examples of aging of enzymes in erythrocytes. It is possible that loss of bound cofactor is a general mechanism for the aging of enzymes.

\section{Introduction}

There are many known variants of human G6PD (EC. 1.1.1.49) which are distinguishable on the basis of electrophoretic or enzymatic properties, heat stability, or $\mathrm{pH}$ optima [16]. Most of these isoenzymes differ by only $5-10 \%$ in their rates of electrophoretic migration. G6PD- $B$, which is the isoenzyme most commonly found in normal individuals, and also the common 
Mediterranean variants migrate on starch gel at a rate that has been designated as $100 \%$. The Canton variant migrates $5 \%$ faster and types $A$ and $A^{-}$migrate $10 \%$ faster than $100 \%$.

We previously studied an isoenzyme [1] which appeared to be type $A$, but anodal migration was $3-4 \%$ faster than that of usual G6PD- $A$ of mature erythrocytes. This fast G6PD- $A$ was seen in the erythrocytes of two infants, and was especially pronounced in a oneweek-old infant. These observations suggest that rapid mobility might be special for the neonate. It was of interest to assess the frequency of this finding and to ascertain whether or not this difference was common to other types of G6PD. This study was initiated in order to answer these questions and to investigate the mechanism of the effect.

\section{Materials and Methods}

Venous blood and cord blood samples were collected from 134 pairs of Negro mothers and their infants [20] in tubes containing acid-citrate-dextrose solution (ACD). Of the subjects, 126 had uncomplicated, full term pregnancies, whereas in 8 there were premature deliveries. Samples were chilled in ice and stored in a refrigerator until analysis.

Hemolysates were prepared and examined for the isoenzymes of G6PD by the method previously reported [1], except that electrophoresis was conducted in precision bore tubes with 3 milliamperes per tube and electrophoresis was continued for an additional 50 min after the albumin marker migrated to the bottom of the tube. This procedure brought normal hemoglobin to within $5 \mathrm{~mm}$ of the bottom of the tube, and it magnified the differences between the zones of the G6PD isoenzymes.

Erythrocytes of normal adults which had the G6PD$B$ isoenzyme were separated into young and old cells by sedimentation [3] and by differential osmotic lysis [12]. Sedimented cells were washed in saline that contained mercaptoethanol and $14 \mu \mathrm{M} \mathrm{NADP}$ and were lysed in 20 volumes of cold water. Salt solution used for differential osmotic lysis contained mercaptoethanol and $14 \mu \mathrm{M}$ NADP.

The following experiments were carried out to characterize further G6PD of young and old cells of adults. Erythrocytes of subjects with the G6PD- $B$ isoenzyme were separated into young and old cells by centrifugation [3] and washed in $0.01 \mathrm{M}$ Tris $\mathrm{HCl}$ buffer, $\mathrm{pH}$ 7.4 , that contained $2.5 \mathrm{~mm} \mathrm{MgCl}_{2}, 0.14 \mathrm{M} \mathrm{KCl}, 0.14$ $\mathrm{mm}$ 2-mercaptoethanol, and either 2.5, 10, or $15 \mu \mathrm{M}$
NADP. Cells were suspended in 9 volumes of the buffer in which they were washed, and they were lysed by freezing and thawing. The resulting lysates were centrifuged $20 \mathrm{~min}$ at $24,000 \times g$ at $4^{\circ}$. To achieve a complete equilibration, $0.4 \mathrm{ml}$ aliquots of clear supernatant were passed through $0.6 \times 11 \mathrm{~cm}$ columns of Sephadex G-25 equilibrated with the same buffers which were used for washing and lysing. Aliquots of the filtrates were then subjected to electrophoresis on $8 \%$ polyacrylamide gels using Tris-glycine buffer, $\mathrm{pH}$ 8.3, that contained $14 \mu \mathrm{M}$ NADP. In experiments in which the effects of NADP were under study, the Trisglycine buffer contained 2.5, 10, or $15 \mu \mathrm{M}$ NADP. Zones of enzyme activity were cleveloped as previously described [1]. Rates of migration of the G6PD of young and old cells were also examined using 6,8 , 10 , and $12 \%$ acrylamide gels [1].

Binding of NADP by G6PD was determined by filtration of hemolysates through $0.6 \times 11 \mathrm{~cm}$ columns of Sephadex G-25 equilibrated with a solution of $2.5 \mathrm{~mm}$ $\mathrm{MgCl}_{2}, 0.14 \mathrm{M} \mathrm{KCl}$, and $0.14 \mathrm{~mm}$ 2-mercaptoethanol containing $15 \mu \mathrm{M}$ NADP (carbonyl) ${ }^{14} \mathrm{C}$. The amount of bound NADP- ${ }^{14} \mathrm{C}$ was established by measuring the ${ }^{14} \mathrm{C}$ content of the breakthrough component containing the macromolecules and of the subsequent fractions containing small molecules including free NADP- ${ }^{14} \mathrm{C}$.

In addition, hemolysates were studied by the method of active enzyme sedimentation analysis [4] in an ultracentrifuge [19] equipped with an ultra violet scanner and a double sector center piece cell [9]. Both sectors of the cell were charged with a buffer solution, $\mathrm{pH}$ 8.3, of the following composition: $7.5 \mathrm{~mm}$ Tris$\mathrm{HCl}, 2.1 \mathrm{~mm} \mathrm{MgCl}_{2}, 10 \mu \mathrm{M}$ NADP, $0.3 \mathrm{~mm}$ glucose-6phosphate, and $2 \mathrm{~m}$ glycerol. Hemolysates were deposited in the sample compartment of one sector and centrifuged at $50,740 \mathrm{rpm}$. The ultra violet scanner was set at $340 \mathrm{~nm}$ and put on the automatic mode of scanning at 8 min intervals.

\section{Results}

In nearly every case, G6PD isoenzymes of erythrocytes of newborn infants migrated toward the anode at rates that were $3-4 \%$ faster than the corresponding isoenzymes of maternal erythrocytes (Fig. 1). This rapid migration of the "fetal" enzyme was evident in hemolysates of erythrocytes from homozygotes or hemizygotes of G6PD types $A, A^{-}$, and $B$. Similar differences were also observed in mother-daughter pairs in which each was heterozygous and had both $A$ and $B$ isoenzymes (Fig. 1). More rapid migration of the 
"fetal" enzyme was independent of sex of the baby and of length of gestation.

Analysis of hemolysates of young and old erythrocytes of adults revealed that G6PD of young, less dense, and osmotically less fragile cells also moved about $3 \%$ faster than that of old, more dense, and osmotically more fragile cells (Fig. 2). In contrast, hemolysates of both young and old erythrocytes, fractionated from cord blood, yielded essentially the same profiles as clid young cells of adults.

When hemolysates of young and old erythrocytes were electrophoresed on $6,8,10$, and $12 \%$ gels for 180

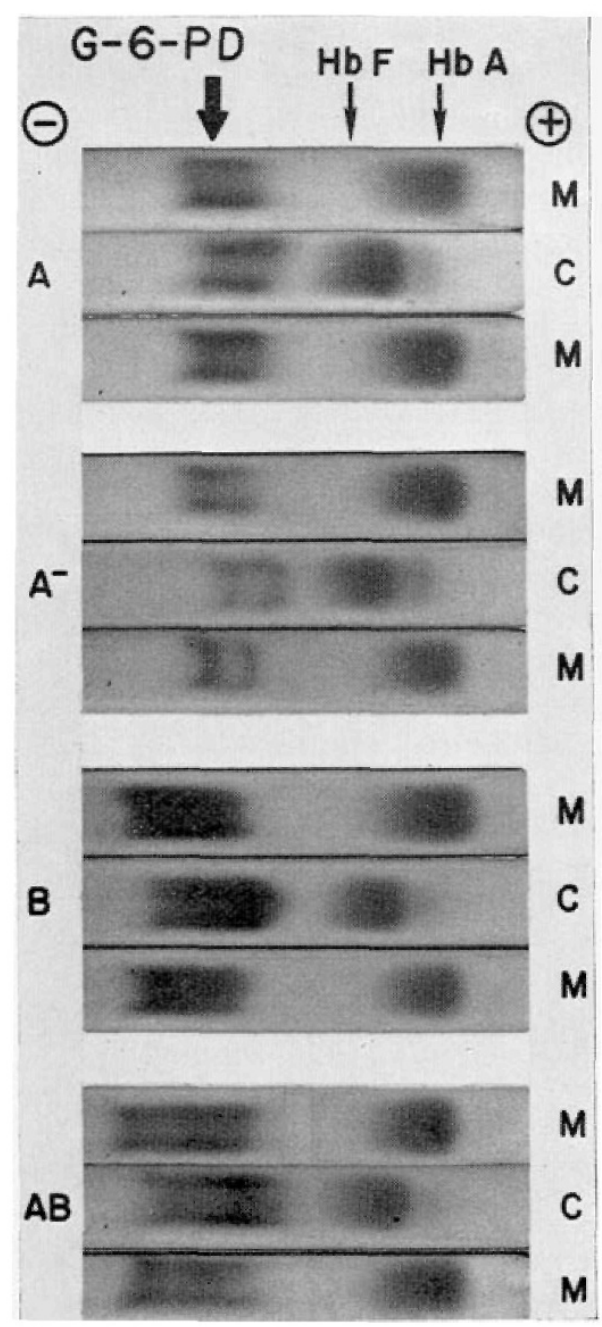

Fig. 1. Electropherograms of G6PD isoenzymes obtained from hemolysates of erythrocytes of mother-infant pairs. The designations $A, A^{-}, B$, and $A B$ on the left of the profiles denote the G6PD variants. The letters $M$ and $C$ on the right designate maternal and cord erythrocytes, respectively. Cells were washed in saline containing 2-mercaptoethanol and $14 \mu \mathrm{M}$ NADP, lysed in water, and electrophoresed at $4^{\circ}$ with 3 milliamperes per tube.

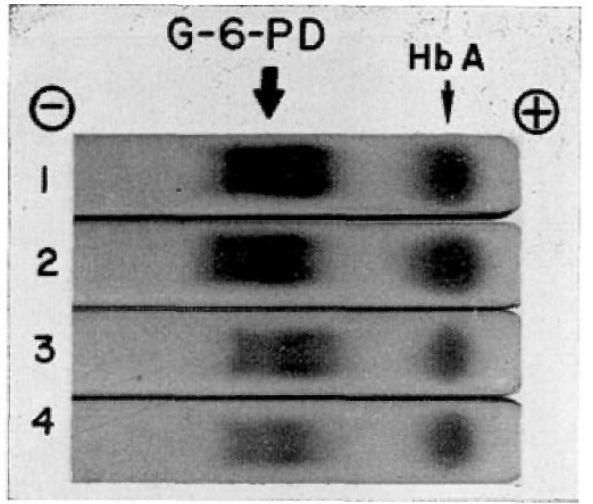

Fig. 2. Electropherograms of $(96 \mathrm{Pl})-A$ isocnzymes of young and old erythrocytes of an adult. Gel I: Jight ervthrocvtes; gel 2: heavy erythrocytes (these cells were treated like those in Fig. 1); gel 3: erythrocytes lysed in $0.06 \mathrm{~m} \mathrm{NaCl}$; and gel $t$ : erythrocytes lysed in $0.08 \mathrm{M} \mathrm{NaCl}$. Both salt solutions contained $14 \mu \mathrm{M} \mathrm{NADP}$. Electrophoresis was conducted at $4^{\circ}$ with 3 milliamperes per tube.

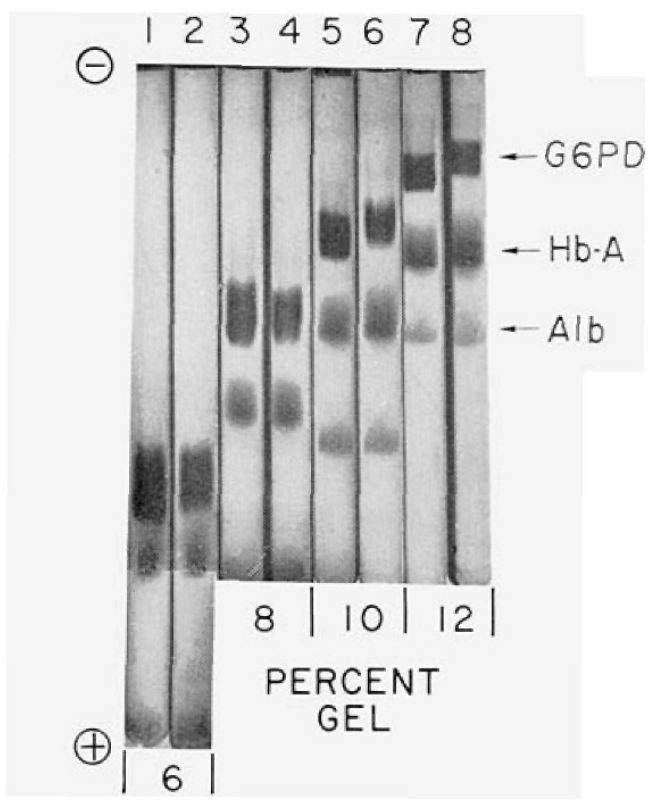

Fig. 3. Effect of acrylamide concentration on the migration of the G6PD of young and old ervthrocytes of adults. Ciels $1,3,5$, and 7 : light erythrocytes; gels 2, 4, 6, and 8 : heavy erythrocytes. Electrophoresis was conducted at $4^{\circ}$ for $180 \mathrm{~min}$ with 3 milliamperes per tube.

min, the migration of albumin, hemoglobin, and G6PD decreased almost linearly with increase in concentration of the gel (Fig. 3). Albumin and hemoglobin migrated at parallel rates while G6PD did not. In Figure 4, the rate of migration relative to albumin $\left(R_{m}\right)$ was calculated and shown for the experiment illustrated in Figure 3. The $\mathrm{R}_{\mathrm{m}}$ of hemoglobin was 0.72 in $6 \%$ gel and 0.73 in $12 \%$ gel. However, the $\mathrm{R}_{\mathrm{m}}$ of the 


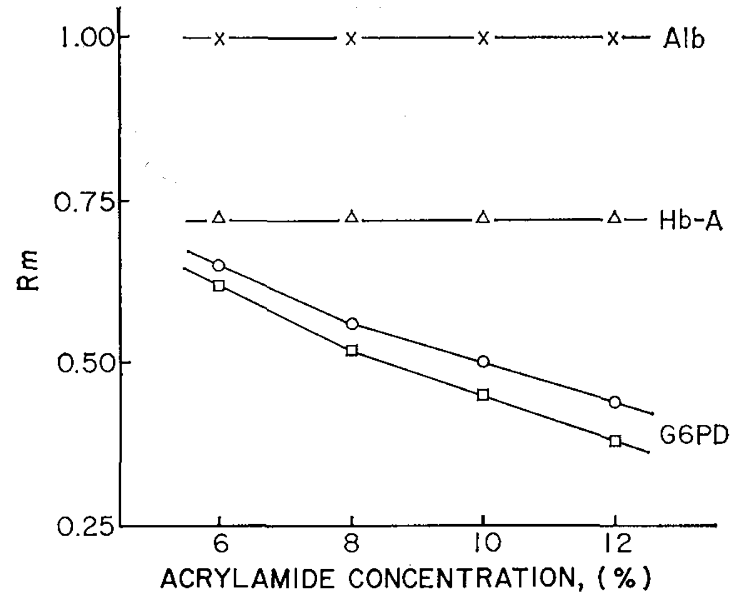

Fig. 4. Relative migration of the G6PD of young and old erythrocytes of adults in gels of different concentrations. $-\mathrm{O}^{-} \mathrm{O}^{-}$: light cells; $-\square-\square-$ : heavy cells.

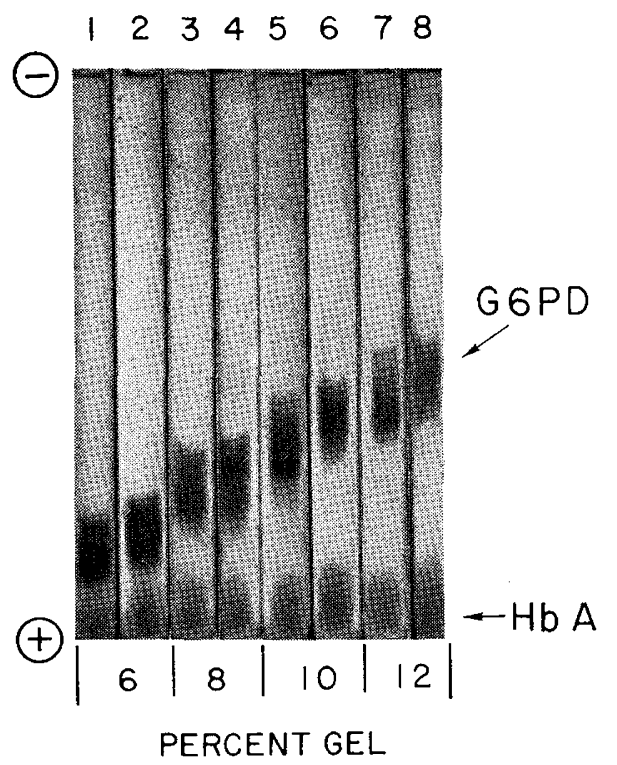

Fig. 5. Effect of acrylamide concentration on electrophoretic migration of the G6PD of young and old erythrocytes of adults. Gels 1, 3, 5, and 7: light erythrocytes; gels 2, 4, 6, and 8 : heavy erythrocytes. Electrophoresis was conducted at $4^{\circ}$ with 3 milliamperes per tube.

G6PD of young cells was 0.65 and 0.44 in 6 and $12 \%$ gels, whereas the $R_{m}$ of the G6PD of old cells was 0.62 and 0.38 , respectively.

In experiments in which hemolysates were electrophoresed until hemoglobin migrated to the bottom of the tubes, rates of migration were considered relative to hemoglobin. In $6 \%$ gel the $\mathrm{R}_{\mathrm{m}}$ of the front of the zone of G6PD from young cells was 0.90 and that of the back of the zone was 0.80 , whereas in $12 \%$ gel these values were 0.66 and 0.51 respectively (Figs. 5 and 6). The $R_{m}$ values to the front and back of the zones of G6PD from old cells were 0.88 and 0.77 , respectively in $6 \%$ gels and 0.62 and 0.48 in $12 \%$ gel. Thus, in $12 \%$ gel the $\mathrm{R}_{\mathrm{m}}$ values of $\mathrm{G} 6 \mathrm{PD}$ of old cells decreased $1.5 \%$ more than did those of G6PD of young cells.

Similar analysis of hemolysate of unfractionated cells on gels of different concentrations yielded G6PD zones that were broader, more diffuse, and, as a rule, lacked clearly defined bonds. In reference to hemoglobin, the $\mathrm{R}_{\mathrm{m}}$ to the front of the G6PD zone in $6 \%$ gel was approximately 0.90 and to the back 0.77 , while in $12 \%$ gel these values were 0.66 and 0.48 . Thus the G6PD zone represented essentially a composite of the enzyme proteins found in fractionated cells.

Molecular size was calculated from the ratio of migration of proteins in gels of different concentrations by the technique of Zwaan [18], using albumin and hemoglobin as references. The molecular size of the G6PD of young cells of adults as calculated in this way was between 118,000 and 119,000, and that of old cells, 121,000-122,000. In contrast, active enzyme sedimenta-

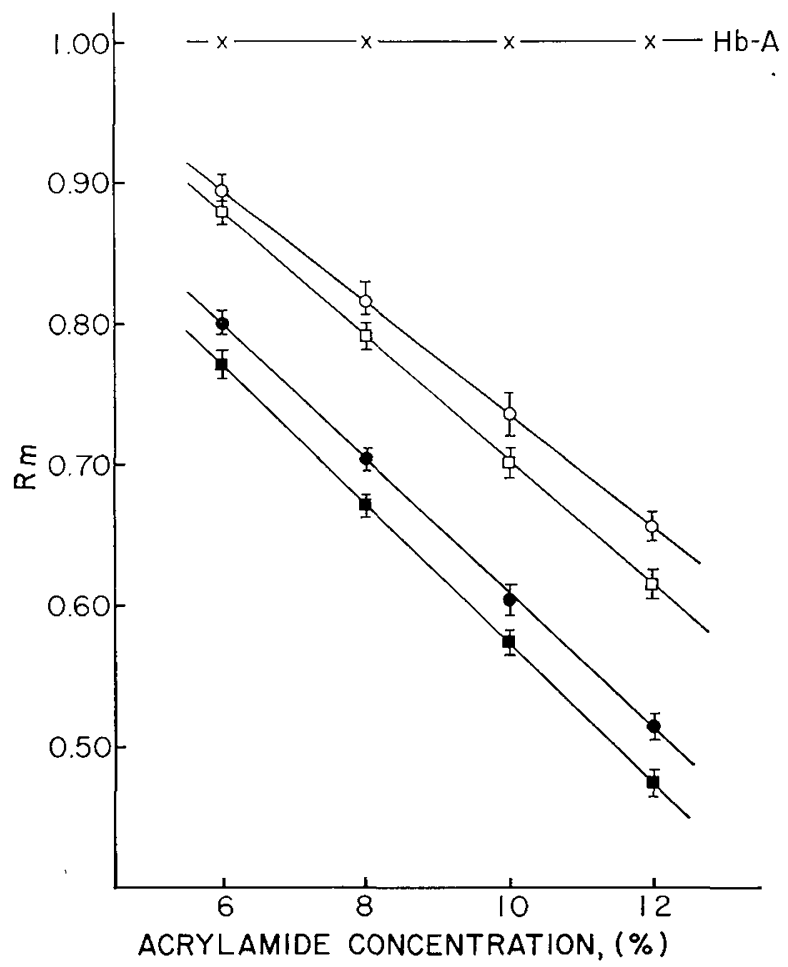

Fig. 6. Relative migration of the G6PD of young and old erythrocytes in gels of different concentrations. $-\mathrm{O}^{-} \mathrm{O}^{-}$: front, and - - -: back of the G6PD zone of old cells; $-\square-\square-$ : front, and : back of the G6PD zone of young cells. 


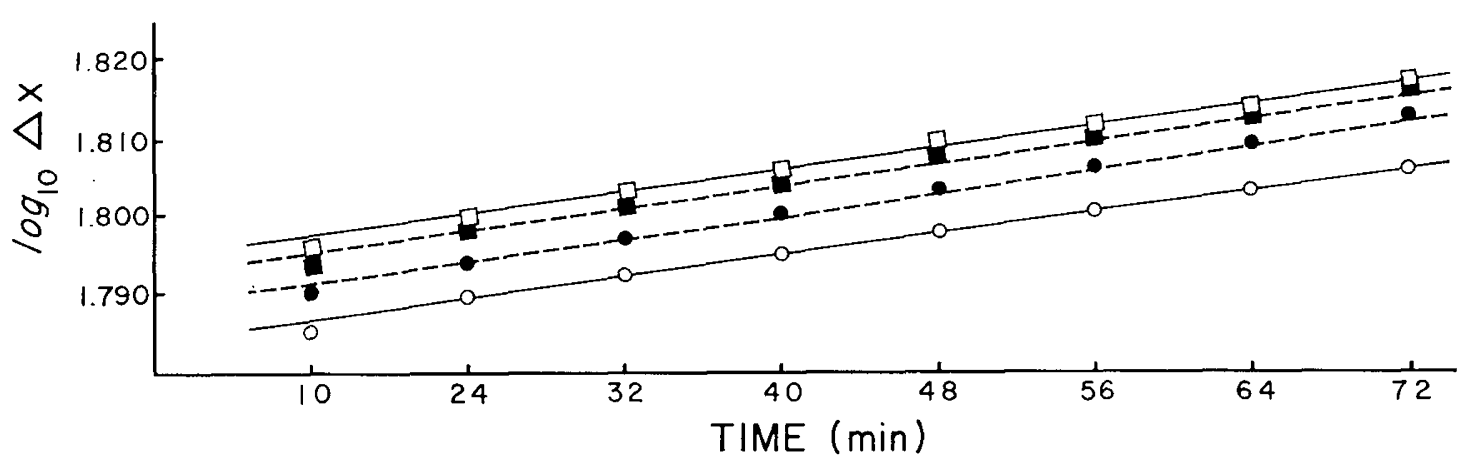

Fig. 7. Rates of sedimentation of G6PD observed by active enzyme sedimentation analysis. -O-O-: young, and - $\square-\square-:$ old erythrocytes of adults; - - : cord blood erythrocytes; - : maternal erythrocytes.

tion analysis revealed that the G6PD enzyme proteins of 1:20 hemolysates of old and young erythrocytes of adults, of newborn babies, and of their mothers sedimented with essentially identical rates (Fig. 7). The average sedimentation coefficients $S_{20, w}$ for the active enzyme proteins were calculated to be 6.8 , which would imply a molecular weight of about 120,000. This was in agreement with the values obtained by other investigators for the purified enzyme protein with Schlieren optics [5] as well as by active enzyme sedimentation analysis [17]. Since the precision of active enzyme sedimentation analysis is about $1 \%$, the molecular weight of G6PD could vary by $\pm 1,200[4]$.

Studies of the effect of NADP revealed that addition of NADP to the buffer used for washing and lysing erythrocytes, as well as to the gels and electrophoretic buffer, did not alter the rates of migration of the G6PD of the various erythrocytes. However, extensive equilibration of hemolysates with NADP by filtration through Sephadex G-25 induced a clear increase in rate of migration (Fig. 8). After such equilibrations with NADP, migration of G6PD of old cells of adults and of mothers at delivery was accelerated by about $3 \%$. Whereas $2.5 \mu \mathrm{M}$ NADP had little effect on the rate of migration of the "old" G6PD enzyme, similar equilibration with 10-15 $\mu \mathrm{M}$ NADP concentration reversed the effects of aging and restored rates of migration to the level characteristic of the enzyme of young cells of adults and of total cell populations of newborn babies (Fig. 9).

When binding of NADP to G6PD was studied using NADP-14 $\mathrm{C}$, the following data were obtained. In the breakthrough or macromolecular component of the Sephadex column, there were 1100-1200 dpm when young cells were studied. In contrast, the breakthrough component from the elution of old cells contained 1800-1900 dpm.

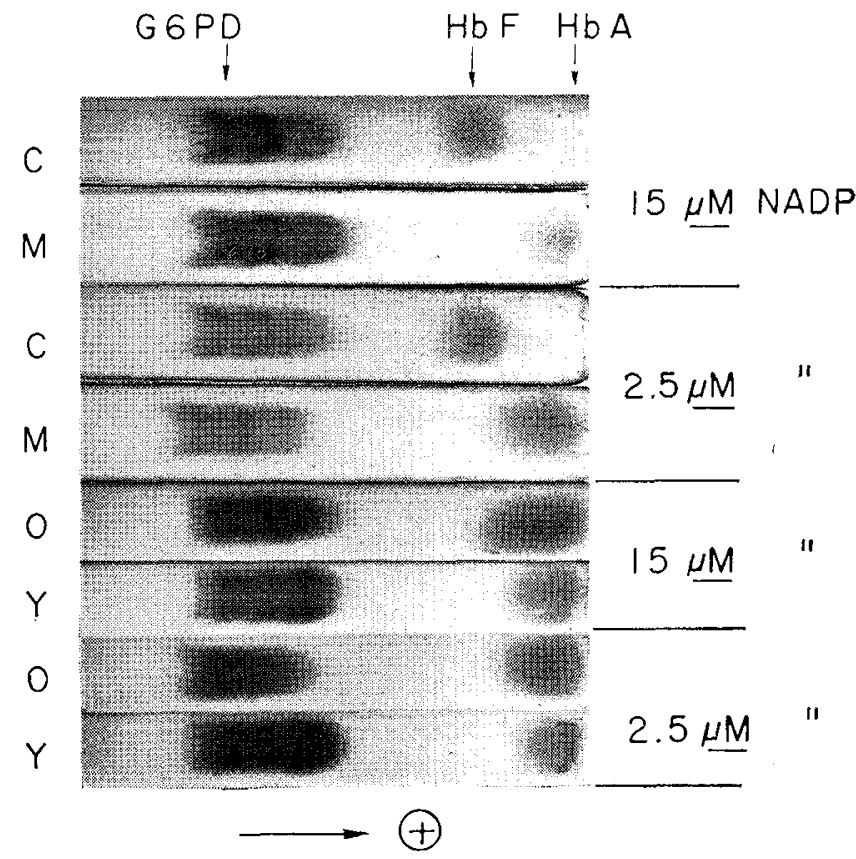

Fig. 8. Effect of equilibration with NADP by filtration through Sephadex $G-25$ on the migration of G6PD. Gels $C$ and $M$ contained hemolysates of cord blood and maternal erythrocytes; gels $Y$ and $O$ contained hemolysates of young (light) and old (heavy) erythrocytes of adults.

\section{Discussion}

This study showed that the rates of migration of G6PD of newborn infants, as observed when hemolysates were electrophoresed on polyacrylamide gel, were faster than those of their mothers. This was true for G6PD types $A, A^{-}$, and $B$, and for the heterozygote with both $A$ and $B$ isoenzymes, regardless of whether the neonate was male or female, full term or premature.

These experiments at first seemed to suggest the ex- 


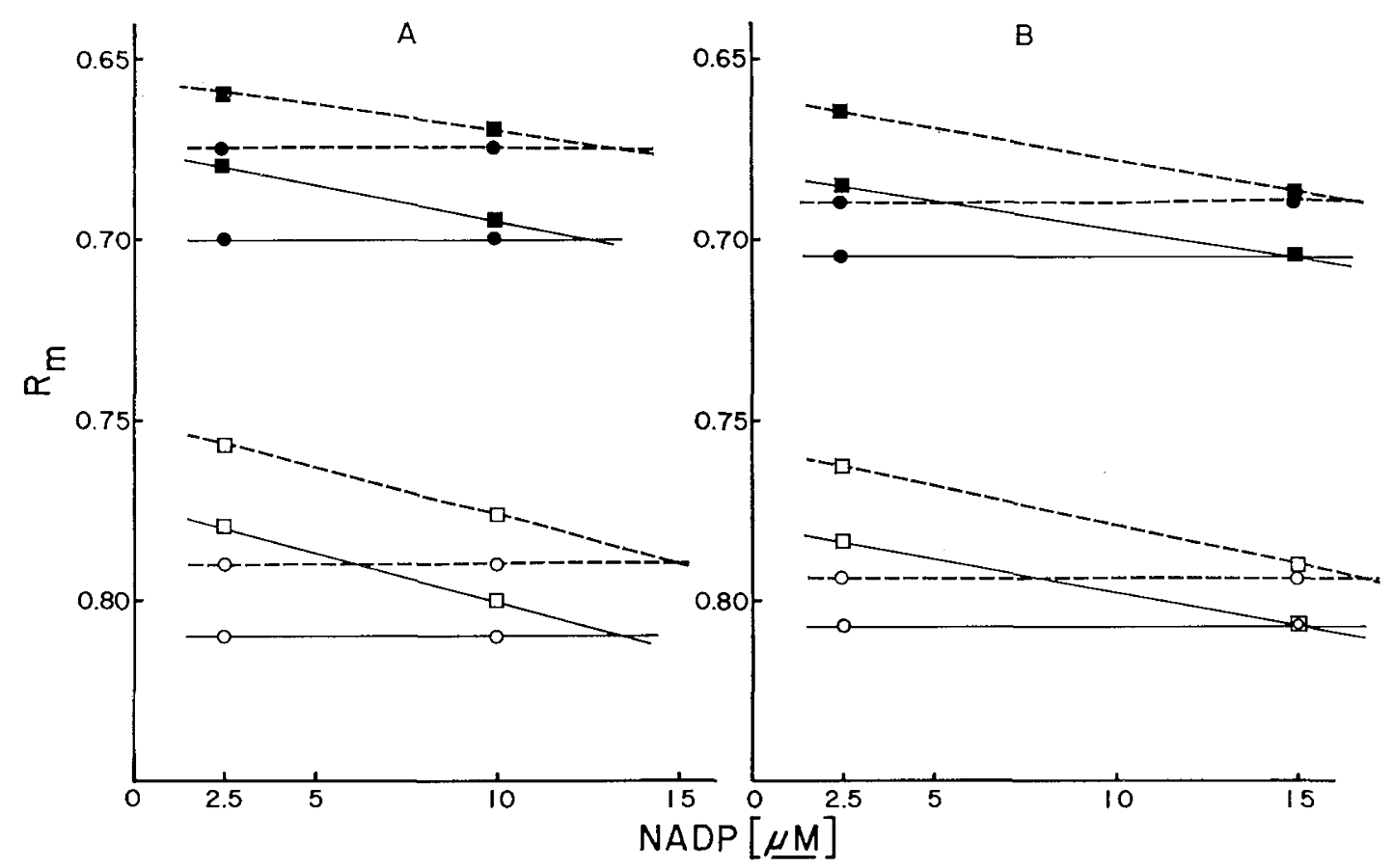

Fig. 9. Effect of equilibration with NADP by filtration through Sephadex G-25 on the rate of migration of G6PD. $A$ : erythrocytes of mature individuals; $B$ : erythrocytes of a neonate and his mother. -O-O-: front, and - - back of the G6PD zone of young and cord blood erythrocytes; $-\square-\square-$ : front, and - - - back of the G6PD zone of old and maternal erythrocytes; $\ldots$ - $20 \mu \mathrm{I}$ and $----: 40 \mu \mathrm{l}$ aliquots of $1: 20$ hemolysates.

istence of a fetal form of G6PD. Such a difference between the protein of infants and that of adults could represent a genetically determined change, as in the case of fetal hemoglobin. An embryonic G6PD variant was reported by Nadler [13] to be present in amniotic cells at 10 -wk gestation. Nevertheless, the faster migrating enzyme of the neonate appears not to represent a specific fetal isoenzyme. It seems more likely that the faster migration of this G6PD is a function of the age of the erythrocytes. Similarly, the quantitative enzymatic activity of G6PD of neonates was usually elevated, and it paralleled the activity found in young cells of mature individuals. On this basis, it has generally been accepted that the erythrocyte population of the neonate consists mainly of young cells [14]. The similarity between the electrophoretic migration of the G6PD of young cells of adults and of neonates, and the observed difference between young and old cells of adults on one hand, and between the neonate and his mother on the other hand, support this view.

It appears that the active form of adult human G6PD is made up of two subunits, one of which is electrophoretically faster than the other. We have postulated that these subunits conjugate, and, when submitted to polyacrylamide gel disc electrophoresis, they yield three bands [1]. Three bands are observed on electrophoresis of G6PD- $A,-A^{-}$, and $-B$ isoenzymes; in the G6PD- $A B$ heterozygote, six bands are seen. The three main variables which govern the electrophoretic migration of proteins in polyacrylamide gel are molecular size, charge, and configuration of the protein molecules. In the case of an enzyme protein, irreversible binding of a substrate, a product, or a conezyme; loss or modification of a functional group; change in configuration resulting in a change in the radius of the protein molecule; or intracellular degradation of the enzyme protein could alter its electrophoretic properties.

Migration in gels of different acrylamide concentrations and velocity sedimentation analysis indicated that the G6PD of old and young erythrocytes was in the same state of aggregation, that it had a molecular weight of approximately 120,000 and possibly represented a dimer. However, the enzyme of old cells appeared to differ from that of young cells with respect to its charge. Acceleration of the migration of "old" G6PD by equilibration with NADP supports this possibility.

It was recently suggested that G6PD dimers with an average sedimentation coefficient of $S_{20, \mathrm{w}}=6.74$ had 3 
sites for binding NADP, I "catalytic" and 2 "structural" [2]. The dissociation constants $\mathrm{Ks}_{1}$ and $\mathrm{Ks}_{2}$ for the catalytic and the 2 structural sites were found to be 45 and $13 \mu \mathrm{M}$ NADP, respectively [10], and, in another study, 20 and $13 \mu \mathrm{M}$ NADP, respectively [6]. Since the G6PD proteins of old and of young cells appear to be in the same state of aggregation, and depletion at structural sites leads to disaggregation of the enzyme, it is unlikely that the structural sites of the "old" enzyme are severely depleted of coenzyme. It is more likely that catalytic sites $\left(\mathrm{Ks}_{1}=20-45 \mu \mathrm{M}\right.$ NADP $)$ are insufficiently charged. It has been found that the activity of G6PD in young cells is considerably greater than that of old cells in the adult [11]. The several-fold decrease in G6PD activity in old cells is consistent with the possibility that there are changes with age in the NADP content of catalytic sites. According to our data, the change which governs the migration of active G6PD is achieved at $14 \mu \mathrm{M}$ NADP concentration. It is concluded that the differences in migration between the enzymes of the neonate and his mother or between the enzymes of young and old cells of the adult result from an in vivo effect of aging which alters the amounts of NADP bound at the catalytic sites. This was in fact confirmed by the demonstration of increased binding of radioactively labeled NADP by the G6PD of old erythrocytes. Differences in the amounts of bound NADP would be expected to produce differences in charge and to result therefore in differences in mobility as well as in enzymatic activity. This is consistent with the effects observed. The effect of in vitro aging on the behavior of enzymes has been studied in lysates which were several days old. For example, the activity of adenosine deaminase decreases as hemolysates are aged in vitro, but its electrophoretic migration in starch gel increases [15]. These changes were found to be due to the state of oxidation of sulfhydryl groups of the enzyme. A similar effect of aging was also observed for nucleoside phosphorylase [8]. These effects have not been examined in young or old cells in vivo. The alteration in the binding of NADP could represent a change in the conformation of the protein during aging. Certainly it was not possible to increase the amount of NADP bound and the electrophoretic mobility of the protein by mixing the enzyme with NADP. These changes took place only when the two were processed together through a Sephadex column, which could have altered conformation during the process to make sites available for binding to NADP. These conclusions are supported by the observation of
Fornaini et al. [7] that the affinity of old G6PD for NADP is decreased.

\section{Summary}

G6PD isoenzymes of erythrocytes of neonates and of young erythrocytes of adults migrated in acrylamide gel 3-4\% faster than the corresponding isoenzymes of maternal exythrocytes or of old erythrocytes of adults. Thorough equilibration of hemolysates of old cells of adults or of cells of mothers at term with NADP induced them to migrate at the same rates as the G6PD of erythrocytes of neonates and of young erythrocytes of adults. Inasmuch as the G6PD of all these cells was in the same state of aggregation, the faster migration of young cells appears to be due to a difference in charge mediated by the amount of NADP bound. This age-dependent change could reflect a change in configuration.

\section{References and Notes}

1. BAKAY, B., AND NyHAN, W. L.: An improved technique for the separation of glucose-6-phosphate dehydrogenase isoenzymes by disc electrophoresis on polyacrylamide gel. Biochem. Genet., 3: 571 (1969).

2. Bonsignore, A., Lorenzoni, I., Cancedda, R., And DeFlora, A.: Distinctive patterns of NADP binding to dimeric and tetrameric glucose-6-phosphate dehydrogenase from human red cells. Biochem. Biophys. Res. Comm., 39: 142 (1970).

3. Borun, R. R., Figueroa, W. G., and Perry, S. M.: The distribution of $\mathrm{Fe}^{50}$ tagged human erythrocytes in centrifuged specimens as a function of cell age. J. Clin. Invest., 36: 676 (1957).

4. Cohen, R., Grraud, B., And Messrah, A.: Theory and practice of the analytical centrifugation of an active substrate-enzyme complex. Biopolymers, 5: 203 (1967).

5. Criss, W. E., and McKerns, K. W.: Purification and partial characterization of glucose-6-phosphate dehydrogenase from cow adrenal cortex. Biochemistry, $7: 125$ (1968).

6. DeFlora, A.: Metabolism of enzyme proteins. Ital. J. Biochem., 17: 365 (1968).

7. Fornaini, G., Leoncini, G., Segni, P., Calabria, G. A., And DACHÀ, M.: Relationship between age and properties of human and rabbit erythrocyte glucose-6-phosphate dehydrogenase. European J. Biochem., 7: 214 (1969).

8. Harris, H.: Personal communication.

9. Kemper, D. L., AND Everse, J.: Active enzyme centrifugation. In: S. N. Timasheff: Methods in Enzymology. (Academic Press, New York) (In press).

10. Luzzarto, L.: Regulation of the activity of glucose-6-phos-

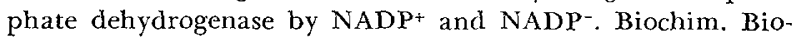
phys. Acta, 146: 18 (1967).

11. Marks, P. A., Johnson, A. B., And Hrrschiberg, E.: Effect of age on the enzyme activity in erythrocytes. Proc. Nat. Acad. Sci. U.S.A., 44: 529 (1958).

12. Marks, P. A., Johnson, A. B., Hirschberg, E., and Banks, J.: 
Studies of the mechanism of aging of human red blood cells. New York Acad. Sci. Ann., 75: 95 (1958).

13. NADLer, H. L.: Patterns of enzyme development utilizing cultivated human fctal cells derived from amniotic fluid. Biochem. Genet., 2: 119 (1968).

14. Oski, F. A., and Naiman, J. L.: Hematologic Problems in the Newborn (W. B. Saunders, Philadelphia, 1966).

15. Spencer, N., Hopkinson, D. A., and Harris, H.: Adenosine deaminase polymorphism in man. Ann. Hum. Genet. Lond., 32: 9 (1968).

16. World Health Organization, Nomenclature of glucose-6phosphate dehydrogenase in man. Acta Genet. Basel, 17: 545 (1967).

17. Yoshida, A., and Hongland, V. D., JR.: Active molecular unit and NADP content of human glucose-6-phosphate dehydrogenase. Biochem. Biophys. Res. Comm., 40: 1167 (1970).

18. ZWANN, J.: Estimation of molecular weights of proteins by polyacrylamide gel clectrophoresis. Anal. Biochem., 21: 155 (1967).
19. Model E, Beckman Spinco, Palo Alto, Calif.

20. Parents of patients were informed about the planned studics in every detail, and consent was obtained prior to the studies.

21. The competent technical assistance of Roswitha Enxight and Carol Wagner is gratefully acknowledged. We also wish to express our appreciation to David Kemper from the Department of Biology, University of California San Diego, for execution of the ultracentrifugal analysis.

22. Supported by L. S. Public Fealth Service Grants nos. HD 04608 and HD 03015 from the National Institute of Child Health and Human Development, National Institutes of Health, and by Grant no. 274 from Health Service and Mental Health Administration, Department of Health, Education and Wclfare.

23. Requests for reprints should be addressed to BOHDAN BAKAY, M.D., Department of Pediatrics, University of California, San Diego, P. O. Box 109, La Jolla, California, 92037 (USA). 24. Accepted for publication April 10, 1972. 